\title{
Risk factors for chronic kidney disease of non-traditional causes: a systematic review
}

\author{
Evelina Chapman, ${ }^{1}$ Michelle M. Haby, ${ }^{2}$ Eduardo Illanes, ${ }^{3}$ Julian Sanchez-Viamonte, ${ }^{4}$ \\ Vanessa Elias, ${ }^{5}$ and Ludovic Reveiz ${ }^{5}$
}

Suggested citation Chapman E, Haby MM, Illanes E, Sanchez-Viamonte J, Elias V, Reveiz L. Risk factors for chronic kidney disease of non-traditional causes: a systematic review. Rev Panam Salud Publica. 2019;43:e35. https://doi.org/10.26633/RPSP.2019.35

ABSTRACT

\begin{abstract}
Objectives. To evaluate the potential associations between chronic kidney disease of uncertain or nontraditional etiology (CKDnT) and agrochemicals, heat stress, heavy metals, and other factors identified in the literature in any region of the world and at any time.

Methods. This was a systematic review of the most frequent exposures suspected to be possible causes of CKDnT. A search was conducted of PubMed, LILACS, World Wide Science electronic databases, among other sources. Only medium- and high-quality studies were included. The synthesis of evidence included a narrative synthesis, meta-analysis, and meta-regression.

Results. Four systematic reviews and 61 primary studies were included. Results of the meta-analysis suggest that exposure to agrochemicals and working in agriculture increase the risk of CKDnT, but this only reached significance for working in agriculture. When cross-sectional studies were excluded, agrochemical exposure became significant. However, there is substantial heterogeneity in the effect sizes.

Conclusions. Based on the existing evidence and the precautionary principle, it is important to implement preventive measures to mitigate the damage caused by CKDnT to both agricultural workers and their communities (i.e., improvement of working conditions, cautious management of agrochemicals, etc.). More high-quality research is needed to measure impact and to build the evidence base.
\end{abstract}

Keywords

Renal insufficiency, chronic; agricultural workers' diseases; agrochemicals; heat exhaustion; meta-analysis.

During the last four decades, a severe form of renal failure has increased among individuals living in socially-vulnerable farming communities of Central America and Asia. In particular, El Salvador and Nicaragua have seen important increases in patients with chronic kidney disease (CKD) and CKD mortality (1). Parts of the Region of the Americas have experienced up to four times the global CKD mortality rate (1).

Chronic kidney disease of uncertain or non-traditional etiology (CKDnT) is a severe form of the disease characterized by progressive renal failure, often diagnosed at a very advanced stage due to the absence of early symptoms; it requires replacement therapy for survival (2). Its etiology is not linked to diabetes, hypertension, glomerulopathies, or other known causes of renal diseases. The clinical, biochemical, and histological characterizations of CKDnT in South Asia, particularly in Sri Lanka, and Central America are very similar $(1-3)$.

The underlying etiologies for CKDnT have not been clearly identified in most regions, but two predominant groups of suspected risk factors have been studied (4). The first group is related to repeated and prolonged exposure to potential toxins,

\footnotetext{
1 Oswaldo Cruz Foundation (Fiocruz), Campus Universitário Darcy Ribeiro, Brasilia, Brazil.

2 Department of Chemical and Biological Sciences, Universidad de Sonora, Hermosillo, Sonora, Mexico.

3 School of Psychology, Universidad Mayor, a Ringgold standard institution, Santiago, Chile.
}

\footnotetext{
4 Informática en Ciencias de la Salud, Escuela Universitaria de Recursos Humanos del Equipo de Salud, Facultad de Ciencias Médicas de la Universidad Nacional de La Plata, Buenos Aires, Argentina.

5 Department of Evidence and Intelligence for Action in Health, Pan American Health Organization/World Health Organization, Washington, DC, United States of America.
} 
including pesticides and heavy metals, in drinking water and in agricultural communities (1). The second is related to heat stress with repeated episodes of dehydration. A recent systematic review of pesticides and CKDnT found scarce evidence for an association with regional CKDnT epidemics, but the role of agrochemicals could not be conclusively discarded based on the evidence available at the time of the review (5).

While there is a general consensus that the patterns of CKDnT are similar in Central America and South Asia, no meta-analysis of all the important risk factors without country limitations had been conducted to date. The objective of this systematic review was to evaluate the potential associations between CKDnT and agrochemicals, heat-stress dehydration, heavy metals, hard water, and other factors described in the literature in any region of the world and at any time.

\section{MATERIALS AND METHODS}

A systematic review and meta-analysis $(6-8)$ were conducted according to the study's previously registered protocol (9). The search included systematic reviews, experimental studies, and observational studies of medium or high quality among any populations with CKDnT. Any exposure implicated in the literature was included as a possible cause of CKDnT, as was any comparison.

The primary outcome was CKDnT defined as estimated glomerular filtration rate $(\mathrm{eGFR})<60 \mathrm{~mL} / \mathrm{min} / 1.73 \mathrm{~m} 2$ body surface area and/or non-nephrotic proteinuria and/or urinary sediment abnormalities as markers of kidney damage and/or renal tubular disorders and exclusion of traditional causes of CKD (2). Acute kidney injury as a proxy outcome measure for studies of heat stress-dehydration was also included.

Studies included were published in English, Spanish, or Portuguese. There was no restriction on the year of publication for systematic reviews; however, for primary studies, only those published after the search dates of the most recent systematic review were included. Searches were conducted of PubMed Central (U.S. National Library of Medicine, Bethesda, Maryland, United States), LILACS (Latin American and Caribbean Center on Health Sciences Information, PAHO/WHO, São Paulo, Brazil), World Wide Science electronic databases (Office of Scientific and Technical Information, U.S. Department of Energy, Oak Ridge, Tennessee, United States), GreenFILE (EBSCO, Ipswich, Massachusetts, United States), AGRIS (Food and Agriculture Organization of the United Nations, Rome, Italy), and PLAGSALUD (MASICA/ OPS) using a combination of subject headings and text words for kidney disease and the potential exposures, developed from previous systematic reviews $(4,5)$. Examples of search strategies are available in the Supplementary Materials. The last search was conducted in August 2017. References and grey literature were also searched, and experts were also consulted. Search results were screened, according to the selection criteria, by one review author; while full texts were retrieved and reviewed against the inclusion criteria by two reviewers. Disagreements were resolved by discussion and consensus.

Data were extracted by one reviewer into Microsoft Word ${ }^{\mathrm{TM}}$ tables (Microsoft Corp., Redmond, Washington, United States), and then checked by a second reviewer. Data extracted included: exposure, study design, sample size, population, country of study, definition of CKDnT, results, funding source, and research gaps. Primary studies already included in systematic reviews did not undergo detailed data extraction or quality assessment, except where required for the meta-analysis. Exposure was classified as: agrochemicals, heavy metals, hard water, heat stress-dehydration, working in agriculture, and other exposures. CKDnT outcomes were classified as: 1 - eGFR with or without non-nephrotic albuminuria; 2 - non-nephrotic albuminuria/ proteinuria; 3 - end-stage renal disease (ESRD); and 4-mortality.

The quality of included studies was assessed by two reviewers. Disagreements were resolved through discussion and consensus. Low quality studies were excluded from the review. For systematic reviews, Assessing the Methodological Quality of Systematic Reviews (AMSTAR) was used (10); scores from $8-11$ were considered to be high quality; from $4-7$ of medium quality; and $0-3$ of low quality.

The Newcastle-Ottawa Quality Assessment Scale was used for cohort studies and case control studies. Scores from $7-9$ were considered to be of high quality; from $4-6$ of medium quality; and from $0-3$ of low quality. Cross-sectional studies were assessed using the adapted RTI Item Bank instrument proposed by the Agency for Healthcare Research and Quality (11).

The synthesis of evidence was based on both a qualitative synthesis and meta-analysis, when possible. This review reports both the effect of the exposure on CKDnT and whether study showed a dose-response relationship between exposure and outcome. Gaps in the research evidence were also identified.

\section{Meta-analysis and meta-regression}

Meta-analysis was used to determine the odds ratio (OR) for each of the main exposures: agrochemicals, heat stressdehydration, heavy metals (including the subcategories arsenic, cadmium, lead, and mercury), hard water, and working in agriculture. ORs were adjusted for other risk factors whenever available, and were chosen because they were the most commonly used statistic in the included primary studies. MetaXL was used to conduct the meta-analysis using the inverse variance heterogeneity method $(12,13)$. Heterogeneity was assessed using Cochran's Q and I I statistics. Doi plots and the LFK index were used to evaluate the presence of small-study effects, where asymmetry can indicate publication or other biases (14).

Given the substantial heterogeneity, a meta-regression was conducted to determine the factors that impact on the effect sizes (6). MetaXL was used to prepare the data for further analysis in Stata ${ }^{\circledR}$ /MP14 (StataCorp LP, College Station, Texas, United States) using the study weights generated $(12,13)$. Effect sizes (lnOR) were transformed. The primary aim of the analysis was to optimize the amount of variance explained using a multivariate linear regression model. A multivariate model was created by adding one factor at a time in order of the amount of variability it explained (R-squared) in univariate analyses. Models were compared using the adjusted R-squared statistic. If the last factor introduced into the model did not increase the adjusted R-squared, it was removed from the model before adding the next factor. The significance of a group of variables was tested using a Wald test.

\section{CKDnT causality considerations}

The various exposures addressed in the literature were compared against the nine considerations for causality of Bradford Hill $(15,16)$. 


\section{RESULTS}

In all, 4 systematic reviews $(4,5,17,18)$ and 61 primary studies were included (19-79), 19 of which came from the search for primary studies $(61-79)$. The selection process for studies and the numbers at each stage are shown in Figure 1. Reasons for exclusion of systematic reviews and primary studies at full text stage, as well as characteristics of included studies and their quality assessment scores are compiled in the Supplementary Materials.

\section{Meta-analysis and meta-regression}

ORs (or equivalent) were available for 56 exposure-control comparisons from 29 studies. As seen in Figures 2 and 3, all exposures had combined ORs $>1$, but this was only consistent for exposure to agrochemicals and working in agriculture, which was also statistically significant. Furthermore, analyses showed substantial heterogeneity, with $\mathrm{I}^{2}$ values from $61 \%-89 \%$ (7). The Doi plots showed major asymmetry for agrochemicals, hard water, and heat stress-dehydration; in contrast, Doi plots also showed only minor asymmetry for working in agriculture and heavy metals. Further details are available in the Supplementary Materials (S5).

The results and interpretation of the meta-regression showed that only exposure and outcome were significant in the multivariate model, but region of study, population of study, and study design were included because they helped to explain the variation in the effect sizes. Together, these variables explained $59 \%$ of the between-study variance in the effect sizes $\left(R^{2}=\right.$ $0.587)$, compared to $9.1 \%$ for exposure alone $\left(R^{2}=0.091\right)$.

\section{Agrochemicals / working in agriculture}

Two systematic reviews $(4,5)$ and 25 primary studies (27 articles; 20, 26, 27, $30-34,38,40-42,44,45,48,50,51,57-59,63$,
$66,67,75,77)$ contributed data on exposure to agrochemicals and/or working in agriculture (see the Supplementary Materials for more details). The majority of studies were conducted in Central America $(n=14)$ or South Asia $(n=7)$.

Agrochemicals. Exposure to agrochemicals increased the risk of CKDnT (OR 1.35; 95\%CI = 0.98 - 1.87; 13 studies), but the result was not significant and there was substantial heterogeneity $\left(\mathrm{I}^{2}=61 \%\right)$, as shown in Figure 2A. When the cross-sectional studies were excluded from the analysis (Figure 2B), the OR increased and became significant (OR 1.44; 95\%CI $=1.02$ $-2.02 ; 9$ studies; $\mathrm{I}^{2}=55 \%$ ). Of 3 studies not included in the metaanalysis (see the Supplementary Materials S6.1), one showed exposure to agrochemicals to be a risk for CKDnT $(31,32)$, though the result was not significant, and the other showed agrochemicals to be protective (34). The third study only had results for specific organochlorine pesticides (63).

Working in agriculture. Working in agriculture was a significant risk for CKDnT (OR 1.78; 95\%CI = $1.21-1.61 ; 17$ comparisons from 15 studies; $\mathrm{I}^{2}=78 \%$ ), as shown in Figure $2 \mathrm{C}$. Of the three studies not included in the meta-analysis, two were positive and statistically significant $(31,32,77)$ and the other (59) did not provide sufficient data to know the direction of the effect (see the Supplementary Materials S6.1).

\section{Heavy metals / hard water}

Three systematic reviews $(4,17,18)$ and 27 primary studies $(19,21$ - 29, 35 - 40, 43, 46, 47, 53, 56, 58, 60 - 62, 73, 76) contributed data on heavy metals and/or hard water. One of the included primary studies contained both cross-sectional and cohort components, with each showing different results (22); and one cross-sectional study also included a case-control

FIGURE 1. Study selection flowchart for systematic review of risk factors for chronic kidney disease of non-traditional causes

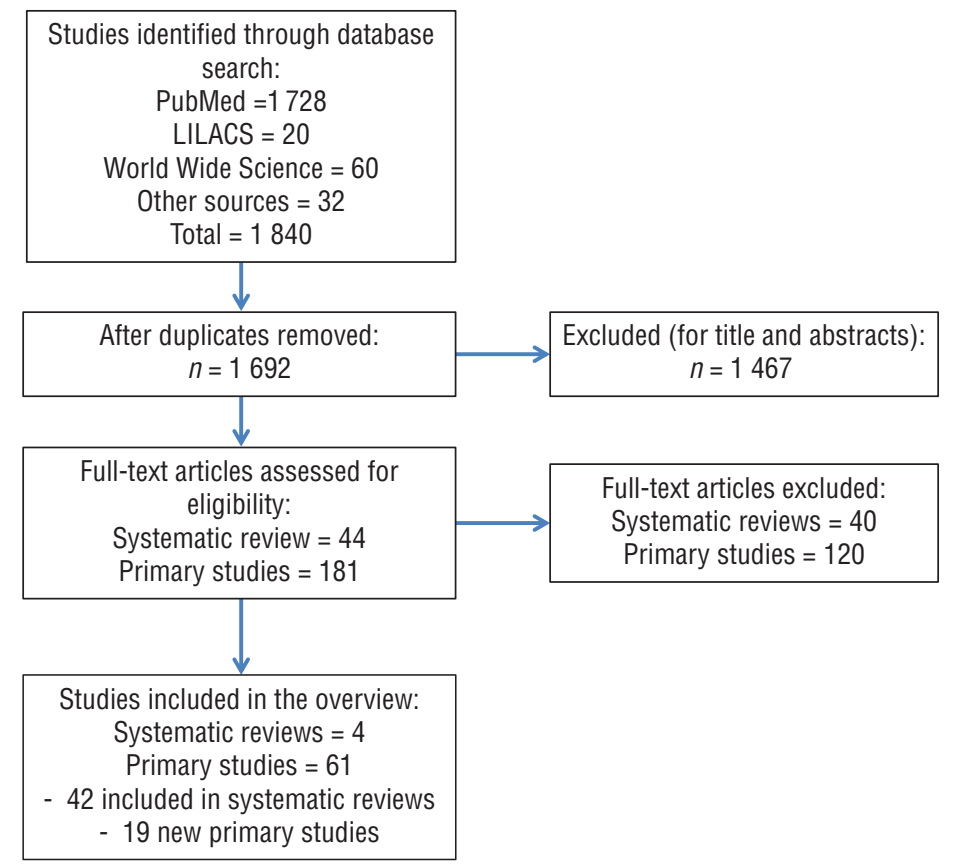

Source: Prepared by the authors from study data. 
FIGURE 2. Forest plots showing the odds ratio for the effect of (A) agrochemicals (all studies); (B) agrochemicals (cross-sectional studies excluded); and (C) working in agriculture on any CKDnT outcome. The summary odds ratio was generated using the inverse variance heterogeneity model.



B. Agrochemicals (cross-sectional studies excluded)

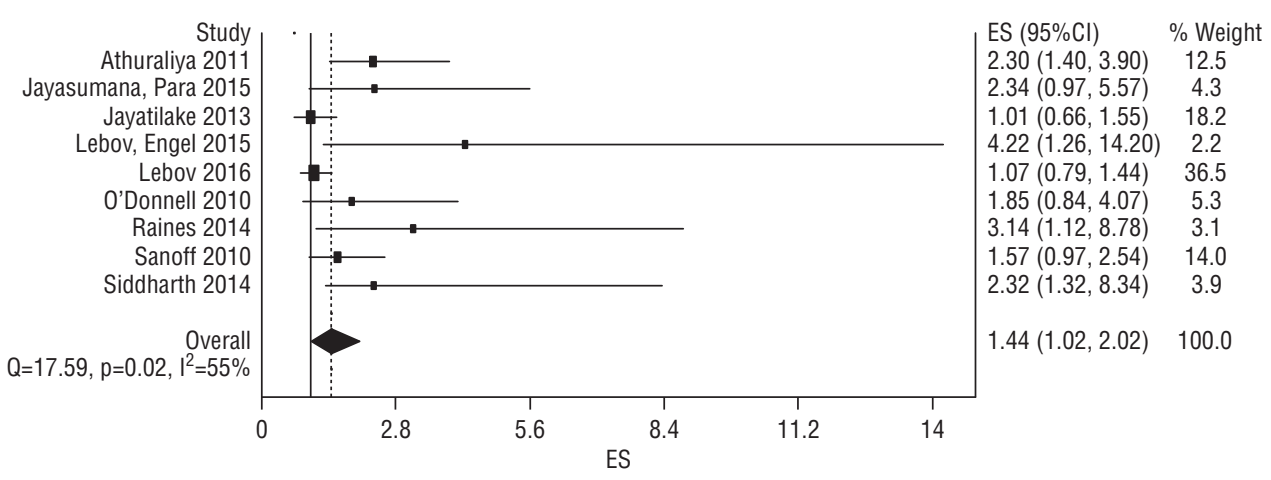

C. Working in agriculture

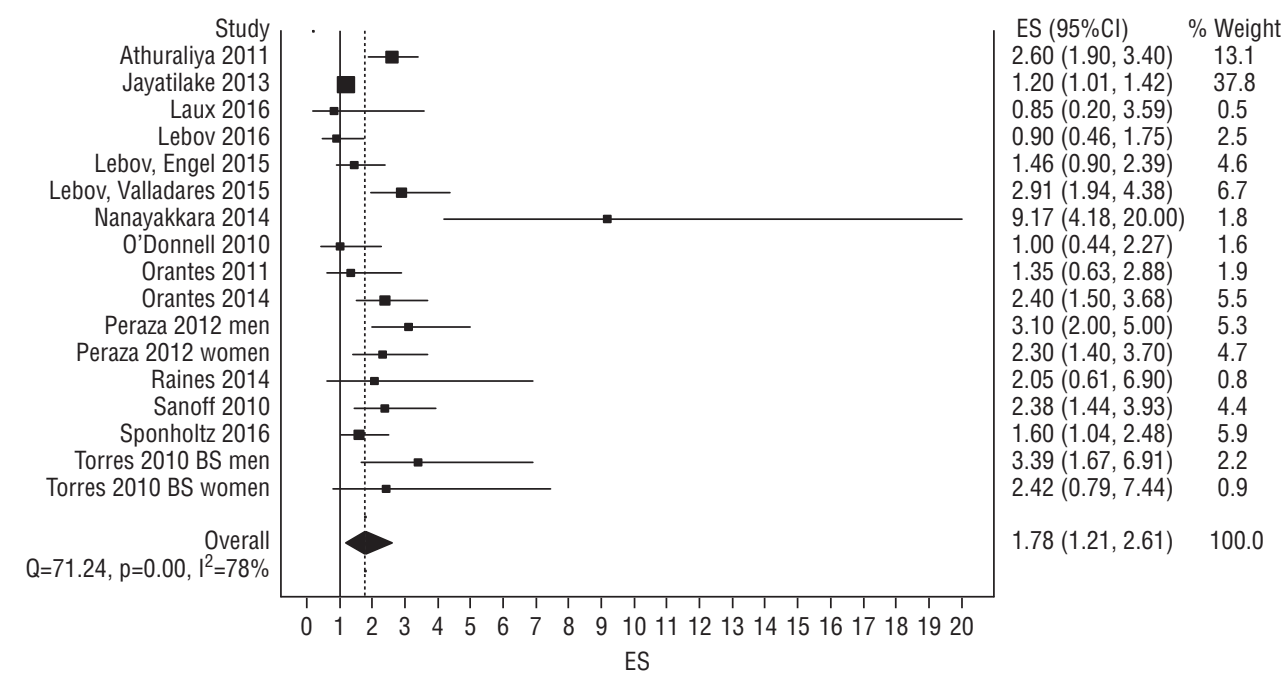

Source: Prepared by the authors from study data. 
FIGURE 3. Forest plots showing the odds ratio for the effect of (A) hard water; (B) heavy metals; and (C) heat stress on any CKDnT outcome. The summary odds ratio was generated using the inverse variance heterogeneity model.

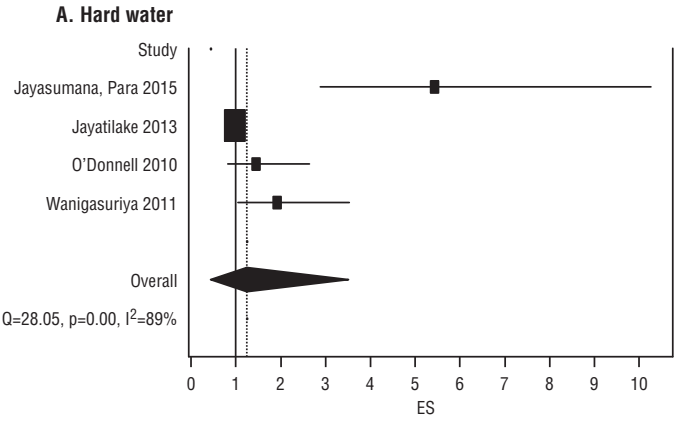

\section{Heat stress}



Source: Prepared by the authors from study data.

component for exposure to heavy metals (27), making a total number of 29 primary studies (see the Supplementary Materials). The majority of studies were conducted in South Asia or non-endemic countries and in adults.

Heavy metals. Exposure to heavy metals increased the risk of CKDnT (OR 1.29; 95\%CI = $0.73-2.28)$, but the result was not significant and had substantial heterogeneity $\left(\mathrm{I}^{2}=87 \%\right)$, as shown in Figure 3B. However, there were four clear subgroups for analysis of results, i.e., arsenic, cadmium, mercury, and lead. This analysis showed that only lead was a significant risk-combined OR 1.38 (95\%CI = $1.01-1.88 ; 4$ studies). Furthermore, there was no significant heterogeneity in the lead results $\left(\mathrm{I}^{2}=0 \%\right)$. As shown in Figure $3 \mathrm{~B}$, the only study of mercury that contributed data to the meta-analysis showed a significant protective effect (OR 0.66; 95\%CI = $0.44-0.98)$; however, only 12 of the 26 primary studies contributed data since the others did not have ORs or equivalents.

When the results from the qualitative analysis were considered (26 studies), the results were less clear (see the Supplementary Materials S6.2). For lead, 9 studies reported results, 4 of which showed exposure to be a risk for CKDnT (all of which were included in the meta-analysis); 3 showed it to be protective; and 2 did not provide sufficient data to know the direction of the effect. Moreover, 3 studies showed a positive doseresponse relationship and 3 found no trend. For arsenic, 5 of the 13 studies showed the exposure to be a risk, while 6 found it to be protective, 5 found a positive and statistically significant dose-response relationship, and 2 found a negative doseresponse relationship. For cadmium, 7 of the 14 studies found exposure to be a risk and 3 found it to be protective. Further, 6 of the 14 studies found a positive dose-response relationship

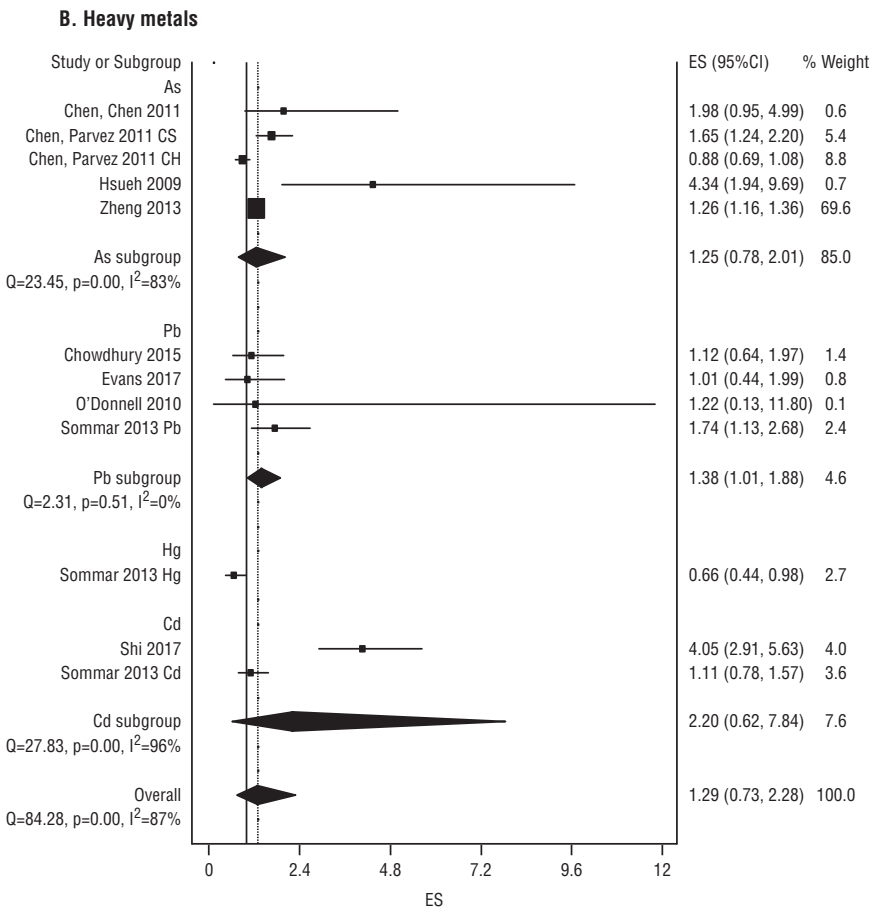

rather than a negative one $(n=1)$. For mercury, the 2 included studies showed a protective effect and 1 of these also found a negative dose-response relationship.

Hard water. Consumption of hard water increased the risk of CKDnT (OR 1.24; 95\%CI $=0.43-3.52 ; 4$ studies), but the result was not significant and had substantial heterogeneity $\left(\mathrm{I}^{2}=89 \%\right)$, as shown in Figure 3A. While 3 of the 4 studies showed hard water to be a risk and 1 also found a positive dose-response effect, a large study showed a small protective effect of hard water (see the Supplementary Materials S6.2). While the 4 included studies were classified as high quality, none were cohort studies.

\section{Heat stress-dehydration (adverse conditions at work)}

One systematic review of medium quality (4) and 8 primary studies $(40,44,45,48,54,65,67,68)$ contributed data on heat stress-dehydration. Five of the primary studies were conducted in Central America and three in non-declared endemic countries (see the Supplementary Materials). All studies used eGFR as the outcome measure with the exception of Moyce (68), which measured acute kidney injury. A wide variety of exposure measures were used as proxy measures of heat stress-dehydration (see the Supplementary Materials S6.3) and the cohort studies all had very short follow-up times.

Exposure to heat stress-dehydration increased the risk of CKDnT (OR 1.36; 95\%CI $=0.84-2.21$ ) according to 7 studies with 10 comparisons $(40,44,45,48,54,65,67)$-results not significant and with substantial heterogeneity $\left(\mathrm{I}^{2}=85 \%\right)$, as shown in Figure 3C. Furthermore, 4 of the 10 comparisons showed a protective effect against CKDnT. The only study 
(68) not included in the meta-analysis used a direct measure of heat stress-dehydration, but measured acute kidney injury instead of CKDnT (see the Supplementary Materials S6.3). Three studies found a positive dose-response relationship between heat stress-dehydration and CKDnT (44, 54, 65), 2 of which were statistically significant $(44,65)$ and 2 found a statistically significant negative dose-response relationship $(48,67)$.

\section{Other exposures}

One systematic review of medium quality (4) and 23 primary studies contributed data on other exposures (20, 27, 38, 40, 41, $44,45,48,49,52,55,58,59,64,67,69-74,78,79)$, with consistent evidence found for the effect of alcohol, smoking, and genetics (Table 1). The evidence for the other exposures was limited and/or inconsistent.

TABLE 1. Characteristics and results of studies that measured the effect of other exposures on CKDnT



a Regions: South Asia $=1$, Central America $=2$, and Non-endemic $=3$, Balkan States $=4$ Study design: $\mathrm{CC}=$ case-control, $\mathrm{CH}=$ cohort, $\mathrm{CS}=$ cross-sectional

- Population: hospital = hospital-based
¿ eGFR (with or without non-nephrotic albuminuria) $=1$, non-nephrotic albuminuria/proteinuria $=2$, end-stage renal disease $=3$, mortality $=4$

$(+)=$ positive; $(-)=$ negative; ( $)$ OR not reported (just $95 \% \mathrm{Cl}$ and $P$ value); $\mathrm{SS}=$ statistically significant effect $(P<0.05)$; NS = not significan Source: Prepared by the authors from study data. 


\section{CKDnT causality considerations}

Assessments of the causality considerations for each of the exposures are shown in Supplementary Materials: agrochemicals and working in agriculture (S7), heavy metals and hard water (S8), heat stress-dehydration (S9), and other exposures (S10). The study also identified research gaps (S11).

\section{DISCUSSION}

\section{Agrochemicals}

We found consistent evidence for the adverse effect of agrochemicals on chronic kidney disease, and in some studies, an association with end-stage renal failure (see the Supplementary Materials). In our meta-analysis, which included 13 studies from different regional areas, the overall effect was positive, and became significant when cross-sectional studies were removed. It is important to stress that high quality studies found significant associations for specific agrochemicals and in regions not declared as "endemic" $(33,34)$. These cohort studies not only involved men and women working as applicators and/or mixers of agrochemicals, but also women married to applicators, both of whom live in the same agricultural environment. Among married women who directly applied pesticides, and among women who did not but whose husbands directly applied specific pesticides, the effect observed was positive and also showed a significant biological gradient over time. The effect was also related to cumulative exposure and to having a well for drinking water, a possible source of agrochemical exposure $(33,34)$.

Although we did not conduct a meta-analysis of specific agrochemicals, there were studies $(33,34)$ of the agrochemical paraquat that was related both by direct exposure (in men) and indirect exposure (in women married to applicators). A study (26) conducted in Sri Lanka found that drinking water from abandoned wells contaminated with glyphosate and heavy metals increased the risk of CKDnT disease by a factor of 5. In Sri Lanka, few cases of the disease have been reported in an area with similar climatic and agricultural conditions, but where glyphosate was banned during the war years (80). Additionally, another review (81) argues that there is compelling evidence that glyphosate exposure is a significant factor in CKDnT in Mesoamerica.

The adverse effects of pesticides on CKDnT could be further aggravated by the presence of chemicals in the soil and drinking water, with possibly cumulative residual effects on soil and water (80). Comparison of biopsy patterns between endemic and non-endemic regions for those with ESRD due to CKDnT could help to clarify whether it is in fact the same disease (1), as has been done for Sri Lanka and Mesoamerica (3).

In relation to biological plausibility, in their systematic review Valcke and colleagues (5) report experimental and clinical evidence to support the claim that a number of pesticides commonly used in many parts of the world are known human nephrotoxins. They reported an effect on acute kidney injury rather than CKD. Experimental studies in animals describe the effect of glyphosate in the kidney with histological patterns and markers of renal failure similar to CKDnT, including genotoxic and teratogenic effects $(80,82)$. A recent study also showed kidney damage from a broad-spectrum glyphosate-based herbicide to glyphosate alone (83). In humans, kidney damage due to acute intoxications, including evolution to chronic renal illness, has also been seen (5).

\section{Metals and hard water}

In this review, 23 primary studies of the association between CKDnT and heavy metals and/or hard water were included, mainly from South Asia and non-endemic countries. There was a generally positive association between exposure to heavy metals and CKDnT, particularly for cadmium and possibly lead, and some evidence from cohort studies to support a temporal relationship (see the Supplementary Materials). The studies of cadmium also showed a positive dose-response gradient. The results for the association of arsenic with CKDnT were mixed, but when the dose-response gradient was measured it was mostly positive. There were only two studies of mercury included, and both showed a protective effect.

Heavy metals, such as cadmium, lead, and mercury are established nephrotoxins at high exposure levels $(84,85)$. Experimental studies reported by a systematic review (18) support the association between arsenic and the development of CKD. The most plausible explanation that was found refers to inflammatory processes and oxidative stress. In one included cohort study the adverse effects of chronic exposure to arsenic were also seen to be reversed with interventions that reduced exposure (22). Some studies have also shown that drinking well water and drinking from abandoned wells-that likely have an even higher concentration of contaminants-in endemic areas increased the risk of CKDnT by 2 and 5 times, respectively (26).

\section{Heat stress-dehydration}

There was no consistent evidence from our systematic review to support the association between CKD and heat stress-dehydration. The studies evaluated assume that changes in osmolarity and other markers in blood and urine provoke repeated episodes of acute renal failure, and from there could lead to the development of CKD. A proposed mechanism by which recurrent or chronic dehydration is capable of causing CKDnT has been put forward by Roncal Jimenez and colleagues (86). It includes increased release of vasopressin, increased oxidative stress by cortical production of uric acid, and hyperuricemia. Meanwhile, two other systematic reviews (one of them of low quality) showed that acute kidney injury is a risk factor for CKD and ESRD in non-agricultural populations and in a hospital environment with known risk factors for $\operatorname{CKD}(87,88)$.

There are reports showing that agricultural workers in Central America are exposed to heat stress $(89-91)$ with periods of recurrent dehydration capable of causing alterations of renal function, mainly acute kidney injury, but with no evidence that these conditions can cause CKD $(48,65,68,87,92)$. Although heat stress and dehydration as causes of chronic kidney damage have some biological plausibility, there are no studies that show indisputably that they are the single or preponderant cause of the onset of the so-called CKDnT. Despite the evidence for the production of chronic kidney damage in animal experiments, there is no solid evidence in humans.

A recent review strongly criticizes the evidence related to heat stress and dehydration as the main cause for CKDnT in Mesoamerica. The authors suggest that, instead, CKDnT is 
probably a toxic nephropathy (93). Also, the mechanization of agricultural labor, as well as the presence of CKD and ESRD in women who do not work physically (as in Sri Lanka), or in non-tropical regions (such as the United States; 34 ) go against the heat stressdehydration hypothesis. Finally, a recent study on the prevalence of early renal damage markers in adolescents with no history of strenuous manual work living in a sugarcane agricultural area with a high number of CKDnT cases would reinforce the role of environmental toxins rather than heat stress-dehydration (94).

\section{Work in agriculture}

This meta-analysis of 15 studies found that working in agriculture significantly increased the risk of having CKD in all regions. The studies included in the qualitative and quantitative synthesis involved nearly 100000 participants. A dose-response relationship also was found in participants of both sexes who work closer to sea level (compared to highlands) in Central America, with risks for both men and women $(44,57)$, as well as those who had worked in agriculture for more than 5 years in a non-endemic region (75). Work in agriculture is a wide context exposure that could also include multiple other exposures such as agrochemicals, heavy metals, and/or heat stressdehydration. It is likely that there is an interaction between these exposures, resulting in varied patterns of damage.

A key strength of this work was the combination of both qualitative and quantitative syntheses, including metaregression, which ensured that all included studies contributed to the main findings, not just those that reported results as ORs. In addition, by including studies from countries not identified as endemic (e.g., Japan, Mexico, the United States), with similar results, it became apparent that the problem of CKDnT goes beyond "endemic" countries and regions.

Limitations. A study limitation worth noting is the considerable heterogeneity of the included primary studies, which limited our ability to make firm conclusions about the state of the evidence. Also, relevant studies published after August 2017 could not be included $(95,96)$.

\section{Conclusions}

This meta-analysis showed a statistically significant association between CKD and pesticide use when cross-sectional studies were excluded. Results for heavy metals, hard water, and heat stress were not consistent. All results had substantial heterogeneity. Several other risk factors have been studied, with consistent evidence found for the effects of alcohol, smoking, and genetics; however, some important and complex gaps in knowledge remain.

Based on the existing evidence and the precautionary principle, it is important to implement preventive measures to mitigate the damage caused by CKDnT to agricultural workers and their communities (i.e., improved working conditions, cautious management of agrochemicals, etc.). More high-quality research is needed to measure impact and to build the evidence base.

Author contributions. EC, LR, MH, and VE wrote the protocol. EC, MH, and EI assessed the main exposures against the Bradford Hill considerations. EC, LR, and VE did the searches. EC and $\mathrm{MH}$ selected studies for inclusion. EC, $\mathrm{MH}, \mathrm{EI}$, and JSV assessed the methodological quality of studies and extracted data. MH did the meta-analysis and meta-regression. All authors reviewed and approved the final version.

Funding. This review was funded by $\mathrm{PAHO} / \mathrm{WHO}$. The views expressed in this article are those of the authors and do not necessarily represent those of PAHO/WHO. The funders had no role in the study design, data collection or analysis, decision to publish, or preparation of the manuscript.

\section{Conflict of interests. None declared.}

Disclaimer. Authors hold sole responsibility for the views expressed in the manuscript, which may not necessarily reflect the opinion or policy of the RPSP/PAJPH or the Pan American Health Organization (PAHO).

\section{REFERENCES}

1. Jayasumana C, Orantes C, Herrera R, Almaguer M, Lopez L, Silva LC, et al. Chronic interstitial nephritis in agricultural communities: a worldwide epidemic with social, occupational and environmental determinants. Nephrol Dial Transplant. 2017;32(2):234-41.

2. Pan American Health Organization. Epidemic of Chronic Kidney Disease in Agricultural Communities in Central America. Case definitions, methodological basis and approaches for public health surveillance. Washington, DC: Pan American Health Organization; 2017 [accessed 4 Dec 2018]. Available from: http://iris.paho.org /xmlui/handle/123456789/34132.

3. Wijkstrom J, Jayasumana C, Dassanayake R, Priyawardane N, Godakanda N, Siribaddana S, et al. Morphological and clinical findings in Sri Lankan patients with chronic kidney disease of unknown cause $(\mathrm{CKDu})$ : Similarities and differences with Mesoamerican Nephropathy. PLoS One. 2018;13(3):e0193056.

4. Lunyera J, Mohottige D, Von Isenburg M, Jeuland M, Patel UD, Stanifer JW. CKD of Uncertain Etiology: A Systematic Review. Clin J Am Soc Nephrol. 2016;11(3):379-85.

5. Valcke M, Levasseur ME, Soares da Silva A, Wesseling C. Pesticide exposures and chronic kidney disease of unknown etiology: an epidemiologic review. Environ Health. 2017;16(1):49.
6. Egger M, Smith GD, Altman DG, editors. Systematic reviews in health care: meta-analysis in context. London: BMJ Publishing Group; 2001.

7. Higgins JPT, Green S, editors. Cochrane Handbook for Systematic Reviews of Interventions Version 5.1.0 [updated March 2011]: The Cochrane Collaboration; 2011 [accessed 4 Dec 2018]. Available from: www.handbook.cochrane.org.

8. Moher D, Liberati A, Tetzlaff J, Altman DG, Group P. Preferred reporting items for systematic reviews and meta-analyses: the PRISMA statement. PLoS Med. 2009;6(7):e1000097.

9. Chapman E, Haby M, Illanes E, Sanchez J, Elias V, Reveiz L. Rapid systematic review protocol: causality framework for chronic kidney disease of non-traditional causes (CKDnT). PROSPERO [Internet]. 2017 [accessed: 4 Dec 2018]; CRD42017076963 Available from: http://www.crd.york.ac.uk/PROSPERO/display_record.php? ID=CRD42017076963.

10. Shea BJ, Grimshaw JM, Wells GA, Boers M, Andersson N, Hamel $\mathrm{C}$, et al. Development of AMSTAR: a measurement tool to assess the methodological quality of systematic reviews. BMC Med Res Methodol. 2007;7:10.

11. Viswanathan M, Berkman ND, Dryden DM, Hartling L. Assessing Risk of Bias and Confounding in Observational Studies of 
Interventions or Exposures: Further Development of the RTI Item Bank. Methods Research Report. (Prepared by RTI-UNC Evidence-based Practice Center under Contract No. 290-2007-10056-I). AHRQ Publication No. 13-EHC106-EF. Rockville, MD: Agency for Healthcare Research and Quality; 2013 [accessed 4 Dec 2018]. Available from: https://www.ncbi.nlm.nih.gov/books/NBK154461/ pdf/Bookshelf_NBK154461.pdf.

12. Barendregt JJ, Doi SA. MetaXL User Guide. Version 5.3. Sunrise Beach, QLD: EpiGear International Pty Ltd; 2011.

13. Doi SA, Barendregt JJ, Khan S, Thalib L, Williams GM. Advances in the meta-analysis of heterogeneous clinical trials I: The inverse variance heterogeneity model. Contemp Clin Trials. 2015;45(Pt A):130-8.

14. Sterne JAC, Egger M, Davey Smith G. Investigating and dealing with publication and other biases. In: Egger M, Davey Smith G, Altman DG, editors. Systematic Reviews in Health Care: Meta-analysis in context. $2^{\text {nd }}$ ed. London: BMJ Publishing Group; 2001. p. 189-208.

15. Hill AB. The Environment and Disease: Association or Causation? Proc R Soc Med. 1965;58:295-300.

16. Lucas RM, McMichael AJ. Association or causation: evaluating links between "environment and disease". Bull World Health Organ. 2005;83(10):792-5.

17. Byber K, Lison D, Verougstraete V, Dressel H, Hotz P. Cadmium or cadmium compounds and chronic kidney disease in workers and the general population: a systematic review. Crit Rev Toxicol. 2016;46(3):191-240.

18. Zheng L, Kuo CC, Fadrowski J, Agnew J, Weaver VM, Navas-Acien A. Arsenic and Chronic Kidney Disease: A Systematic Review. Curr Environ Health Rep. 2014;1(3):192-207.

19. Adams RG. An analysis of mortality from nephritis and nephrosis among nickel-cadmium battery workers (edited proceedings). In: Wilson D, Volpe RA, editors. Cadmium 83 Fourth International Cadmium Conference; Munich. London, New York: Cadmium Association; Cadmium Council Inc.; International Lead Zinc Research Association; 1983. p. 155-6.

20. Athuraliya NT, Abeysekera TD, Amerasinghe PH, Kumarasiri $\mathrm{R}$, Bandara $\mathrm{P}$, Karunaratne $\mathrm{U}$, et al. Uncertain etiologies of proteinuric-chronic kidney disease in rural Sri Lanka. Kidney Int. 2011;80(11):1212-21.

21. Chen JW, Chen HY, Li WF, Liou SH, Chen CJ, Wu JH, et al. The association between total urinary arsenic concentration and renal dysfunction in a community-based population from central Taiwan. Chemosphere. 2011;84(1):17-24.

22. Chen Y, Parvez F, Liu M, Pesola GR, Gamble MV, Slavkovich V, et al. Association between arsenic exposure from drinking water and proteinuria: results from the Health Effects of Arsenic Longitudinal Study. Int J Epidemiol. 2011;40(3):828-35.

23. Hawkesworth S, Wagatsuma Y, Kippler M, Fulford AJ, Arifeen $\mathrm{SE}$, Persson LA, et al. Early exposure to toxic metals has a limited effect on blood pressure or kidney function in later childhood, rural Bangladesh. Int J Epidemiol. 2013;42(1):176-85.

24. Hotz P, Buchet JP, Bernard A, Lison D, Lauwerys R. Renal effects of low-level environmental cadmium exposure: 5-year follow-up of a subcohort from the Cadmibel study. Lancet. 1999;354(9189):1508-13.

25. Hsueh YM, Chung CJ, Shiue HS, Chen JB, Chiang SS, Yang MH, et al. Urinary arsenic species and CKD in a Taiwanese population: a case-control study. Am J Kidney Dis. 2009;54(5):859-70.

26. Jayasumana C, Paranagama P, Agampodi S, Wijewardane C, Gunatilake S, Siribaddana S. Drinking well water and occupational exposure to herbicides is associated with chronic kidney disease in Padavi-Sripura, Sri Lanka. Environ Health. 2015;14:6.

27. Jayatilake N, Mendis S, Maheepala P, Mehta FR, CKDu National Research Project Team. Chronic kidney disease of uncertain aetiology: prevalence and causative factors in a developing country. BMC Nephrol. 2013;14:180.

28. Karmaus W, Dimitrov P, Simeonov V, Tsolova S, Bonev A, Georgieva R. Metals and kidney markers in adult offspring of endemic nephropathy patients and controls: a two-year follow-up study. Environ Health. 2008;7:11.

29. Kong AP, Xiao K, Choi KC, Wang G, Chan MH, Ho CS, et al. Associations between microRNA (miR-21, 126, 155 and 221), albuminuria and heavy metals in Hong Kong Chinese adolescents. Clin Chim Acta. 2012;413(13-14):1053-7.

30. Laux TS, Bert PJ, Barreto Ruiz GM, Gonzalez M, Unruh M, Aragon A, et al. Nicaragua revisited: evidence of lower prevalence of chronic kidney disease in a high-altitude, coffee-growing village. J Nephrol. 2012;25(4):533-40.

31. Laws RL, Brooks DR, Amador JJ, Weiner DE, Kaufman JS, RamirezRubio $\mathrm{O}$, et al. Changes in kidney function among Nicaraguan sugarcane workers. Int J Occup Environ Health. 2015;21(3):241-50.

32. Laws RL, Brooks DR, Amador JJ, Weiner DE, Kaufman JS, Ramirez-Rubio O, et al. Biomarkers of Kidney Injury Among Nicaraguan Sugarcane Workers. Am J Kidney Dis. 2016;67(2):209-17.

33. Lebov JF, Engel LS, Richardson D, Hogan SL, Hoppin JA, Sandler DP. Pesticide use and risk of end-stage renal disease among licensed pesticide applicators in the Agricultural Health Study. Occup Environ Med. 2016;73(1):3-12.

34. Lebov JF, Engel LS, Richardson D, Hogan SL, Sandler DP, Hoppin JA. Pesticide exposure and end-stage renal disease risk among wives of pesticide applicators in the Agricultural Health Study. Environ Res. 2015;143(Pt A):198-210.

35. Liang Y, Lei L, Nilsson J, Li H, Nordberg M, Bernard A, et al. Renal function after reduction in cadmium exposure: an 8-year follow-up of residents in cadmium-polluted areas. Environ Health Perspect. 2012;120(2):223-8.

36. Maruzeni S, Nishijo M, Nakamura K, Morikawa Y, Sakurai M, Nakashima M, et al. Mortality and causes of deaths of inhabitants with renal dysfunction induced by cadmium exposure of the polluted Jinzu River basin, Toyama, Japan; a 26-year follow-up. Environ Health. 2014;13(1):18.

37. Mayer DR, Kosmus W, Pogglitsch H, Mayer D, Beyer W. Essential trace elements in humans. Serum arsenic concentrations in hemodialysis patients in comparison to healthy controls. Biol Trace Elem Res. 1993;37(1):27-38.

38. Nanayakkara S, Senevirathna ST, Abeysekera T, Chandrajith R, Ratnatunga N, Gunarathne ED, et al. An integrative study of the genetic, social and environmental determinants of chronic kidney disease characterized by tubulointerstitial damages in the North Central Region of Sri Lanka. J Occup Health. 2014;56(1):28-38.

39. Nanayakkara S, Senevirathna ST, Karunaratne U, Chandrajith R, Harada KH, Hitomi T, et al. Evidence of tubular damage in the very early stage of chronic kidney disease of uncertain etiology in the North Central Province of Sri Lanka: a cross-sectional study. Environ Health Prev Med. 2012;17(2):109-17.

40. O'Donnell JK, Tobey M, Weiner DE, Stevens LA, Johnson S, Stringham $\mathrm{P}$, et al. Prevalence of and risk factors for chronic kidney disease in rural Nicaragua. Nephrol Dial Transplant. 2011;26(9):2798-805.

41. Orantes CM, Herrera R, Almaguer M, Brizuela EG, Hernandez CE, Bayarre $\mathrm{H}$, et al. Chronic kidney disease and associated risk factors in the Bajo Lempa region of El Salvador: Nefrolempa study, 2009. MEDICC Rev. 2011;13(4):14-22.

42. Orantes CM, Herrera R, Almaguer M, Brizuela EG, Nunez L, Alvarado NP, et al. Epidemiology of chronic kidney disease in adults of Salvadoran agricultural communities. MEDICC Rev. 2014;16(2):23-30.

43. Palaneeswari MS, Rajan PM, Silambanan S, Jothimalar. Blood Arsenic and Cadmium Concentrations in End-Stage Renal Disease Patients who were on Maintenance Haemodialysis. J Clin Diagn Res. 2013;7(5):809-13.

44. Peraza S, Wesseling C, Aragon A, Leiva R, Garcia-Trabanino RA, Torres $C$, et al. Decreased kidney function among agricultural workers in El Salvador. Am J Kidney Dis. 2012;59(4):531-40.

45. Raines N, Gonzalez M, Wyatt C, Kurzrok M, Pool C, Lemma T, et al. Risk factors for reduced glomerular filtration rate in a Nicaraguan community affected by Mesoamerican nephropathy. MEDICC Rev. 2014;16(2):16-22.

46. Robles-Osorio ML, Perez-Maldonado IN, Martin del Campo D, Montero-Perea D, Aviles-Romo I, Sabath-Silva E, et al. Urinary arsenic levels and risk of renal injury in a cross-sectional study in open population. Rev Invest Clin. 2012;64(6 Pt 2):609-14.

47. Roels HA, Lauwerys RR, Buchet JP, Bernard AM, Vos A, Oversteyns $M$. Health significance of cadmium induced renal dysfunction: a five year follow up. Br J Ind Med. 1989;46(11):755-64.

48. Sanoff SL, Callejas L, Alonso CD, Hu Y, Colindres RE, Chin H, et al. Positive association of renal insufficiency with agriculture employment and unregulated alcohol consumption in Nicaragua. Ren Fail. 2010;32(7):766-77.

49. Siddarth M, Datta SK, Ahmed RS, Banerjee BD, Kalra OP, Tripathi AK. Association of CYP1A1 gene polymorphism with chronic 
kidney disease: a case control study. Environ Toxicol Pharmacol. 2013;36(1):164-70.

50. Siddharth M, Datta SK, Bansal S, Mustafa M, Banerjee BD, Kalra OP, et al. Study on organochlorine pesticide levels in chronic kidney disease patients: association with estimated glomerular filtration rate and oxidative stress. J Biochem Mol Toxicol. 2012;26(6):241-7.

51. Siddharth M, Datta SK, Mustafa M, Ahmed RS, Banerjee BD, Kalra $\mathrm{OP}$, et al. Increased level of organochlorine pesticides in chronic kidney disease patients of unknown etiology: role of GSTM1/GSTT1 polymorphism. Chemosphere. 2014;96:174-9.

52. Siriwardhana EA, Perera PA, Sivakanesan R, Abeysekara T, Nugegoda DB, Weerakoon KG. Is the staple diet eaten in Medawachchiya, Sri Lanka, a predisposing factor in the development of chronic kidney disease of unknown etiology? - A comparison based on urinary beta2-microglobulin measurements. BMC Nephrol. 2014;15:103.

53. Sommar JN, Svensson MK, Bjor BM, Elmstahl SI, Hallmans G, Lundh T, et al. End-stage renal disease and low level exposure to lead, cadmium and mercury; a population-based, prospective nested case-referent study in Sweden. Environ Health. 2013;12:9.

54. Sontrop JM, Dixon SN, Garg AX, Buendia-Jimenez I, Dohein O, Huang SH, et al. Association between water intake, chronic kidney disease, and cardiovascular disease: a cross-sectional analysis of NHANES data. Am J Nephrol. 2013;37(5):434-42.

55. Stanifer JW, Maro V, Egger J, Karia F, Thielman N, Turner EL, et al. The epidemiology of chronic kidney disease in Northern Tanzania: a population-based survey. PLoS One. 2015;10(4):e0124506.

56. Swaddiwudhipong W, Limpatanachote P, Mahasakpan P, Krintratun S, Punta B, Funkhiew T. Progress in cadmium-related health effects in persons with high environmental exposure in northwestern Thailand: a five-year follow-up. Environ Res. 2012;112:194-8.

57. Torres C, Aragon A, Gonzalez M, Lopez I, Jakobsson K, Elinder CG, et al. Decreased kidney function of unknown cause in Nicaragua: a community-based survey. Am J Kidney Dis. 2010;55(3):485-96.

58. Wanigasuriya KP, Peiris-John RJ, Wickremasinghe R. Chronic kidney disease of unknown aetiology in Sri Lanka: is cadmium a likely cause? BMC Nephrol. 2011;12:32.

59. Wesseling C, Aragon A, Gonzalez M, Weiss I, Glaser J, Rivard CJ, et al. Heat stress, hydration and uric acid: a cross-sectional study in workers of three occupations in a hotspot of Mesoamerican nephropathy in Nicaragua. BMJ Open. 2016;6(12):e011034.

60. Zheng LY, Umans JG, Tellez-Plaza M, Yeh F, Francesconi KA, Goessler W, et al. Urine arsenic and prevalent albuminuria: evidence from a population-based study. Am J Kidney Dis. 2013;61(3):385-94.

61. Chowdhury R, Mukhopadhyay A, McClellan W, Sarnat S, Darrow L, Steenland K. Survival patterns of lead-exposed workers with end-stage renal disease from Adult Blood Lead Epidemiology and Surveillance program. Am J Med Sci. 2015;349(3):222-7.

62. Evans M, Discacciati A, Quershi AR, Akesson A, Elinder CG. Endstage renal disease after occupational lead exposure: 20 years of follow-up. Occup Environ Med. 2017;74(6):396-401.

63. Ghosh R, Siddarth M, Singh N, Tyagi V, Kare PK, Banerjee BD, et al. Organochlorine pesticide level in patients with chronic kidney disease of unknown etiology and its association with renal function. Environ Health Prev Med. 2017;22(1):49.

64. Jelakovic B, Vukovic Lela I, Karanovic S, Dika Z, Kos J, Dickman K, et al. Chronic dietary exposure to aristolochic acid and kidney function in native farmers from a Croatian endemic area and Bosnian immigrants. Clin J Am Soc Nephrol. 2015;10(2):215-23.

65. Kuwabara M, Hisatome I, Roncal-Jimenez CA, Niwa K, Andres-Hernando A, Jensen T, et al. Increased Serum Sodium and Serum Osmolarity Are Independent Risk Factors for Developing Chronic Kidney Disease; 5 Year Cohort Study. PLoS One. 2017;12(1):e0169137.

66. Laux TS, Barnoya J, Cipriano E, Herrera E, Lopez N, Polo VS, et al. Prevalence of chronic kidney disease of non-traditional causes in patients on hemodialysis in southwest Guatemala. Rev Panam Salud Publica. 2016;39(4):186-93.

67. Lebov JF, Valladares E, Pena R, Pena EM, Sanoff SL, Cisneros EC, et al. A population-based study of prevalence and risk factors of chronic kidney disease in Leon, Nicaragua. Can J Kidney Health Dis. 2015;2:6.

68. Moyce S, Mitchell D, Armitage T, Tancredi D, Joseph J, Schenker M. Heat strain, volume depletion and kidney function in California agricultural workers. Occup Environ Med. 2017;74(6):402-9.
69. Nanayakkara S, Senevirathna ST, Parahitiyawa NB, Abeysekera $\mathrm{T}$, Chandrajith R, Ratnatunga N, et al. Whole-exome sequencing reveals genetic variants associated with chronic kidney disease characterized by tubulointerstitial damages in North Central Region, Sri Lanka. Environ Health Prev Med. 2015;20(5):354-9.

70. Riefkohl A, Ramirez-Rubio O, Laws RL, McClean MD, Weiner DE, Kaufman JS, et al. Leptospira seropositivity as a risk factor for Mesoamerican Nephropathy. Int J Occup Environ Health. 2017:1-10.

71. Sayanthooran S, Magana-Arachchi DN, Gunerathne L, Abeysekera T. Potential diagnostic biomarkers for chronic kidney disease of unknown etiology (CKDu) in Sri Lanka: a pilot study. BMC Nephrol. 2017;18(1):31.

72. Sayanthooran S, Magana-Arachchi DN, Gunerathne L, Abeysekera TD, Sooriyapathirana SS. Upregulation of Oxidative Stress Related Genes in a Chronic Kidney Disease Attributed to Specific Geographical Locations of Sri Lanka. Biomed Res Int. 2016;2016:7546265. Epub 2016 Nov 16.

73. Shi Z, Taylor AW, Riley M, Byles J, Liu J, Noakes M. Association between dietary patterns, cadmium intake and chronic kidney disease among adults. Clin Nutr. 2018;37(1):276-284

74. Siriwardhana EA, Perera PA, Sivakanesan R, Abeysekara T, Nugegoda DB, Jayaweera JA. Dehydration and malaria augment the risk of developing chronic kidney disease in Sri Lanka. Indian J Nephrol. 2015;25(3):146-51.

75. Sponholtz TR, Sandler DP, Parks CG, Applebaum KM. Occupational exposures and chronic kidney disease: Possible associations with endotoxin and ultrafine particles. Am J Ind Med. 2016;59(1):1-11.

76. Tsai CC, Wu CL, Kor CT, Lian IB, Chang CH, Chang TH, et al. Prospective associations between environmental heavy metal exposure and renal outcomes in adults with chronic kidney disease. Nephrol. 2018;23(9):830-6.

77. Wesseling C, Aragon A, Gonzalez M, Weiss I, Glaser J, Bobadilla NA, et al. Kidney function in sugarcane cutters in Nicaragua--A longitudinal study of workers at risk of Mesoamerican nephropathy. Environ Res. 2016;147:125-32.

78. Xing $\mathrm{X}$, Lu J, Wang Z. Associated risk factors for chronic kidney disease of unknown etiologies in 241 patients. Int J Artif Organs. 2015;38(4):184-91.

79. Yang HY, Hung CC, Liu SH, Guo YG, Chen YC, Ko YC, et al. Overlooked Risk for Chronic Kidney Disease after Leptospiral Infection: A Population-Based Survey and Epidemiological Cohort Evidence. PLoS Negl Trop Dis. 2015;9(10):e0004105.

80. Jayasumana C, Gunatilake S, Senanayake P. Glyphosate, hard water and nephrotoxic metals: are they the culprits behind the epidemic of chronic kidney disease of unknown etiology in Sri Lanka? Int J Environ Res Public Health. 2014;11(2):2125-47.

81. Seneff S, Orlando LF. Is glyphosate a key factor in Mesoamerican Nephropathy? J Environ Anal Toxicol. 2018;7:542.

82. Ghisi Nde C, de Oliveira EC, Prioli AJ. Does exposure to glyphosate lead to an increase in the micronuclei frequency? A systematic and meta-analytic review. Chemosphere. 2016;145:42-54.

83. Dedeke GA, Owagboriaye FO, Ademolu KO, Olujimi OO, Aladesida AA. Comparative Assessment on Mechanism Underlying Renal Toxicity of Commercial Formulation of Roundup Herbicide and Glyphosate Alone in Male Albino Rat. Int J Toxicol. 2018;37(4):285-295.

84. Jayasumana C, Gunatilake S, Siribaddana S. Simultaneous exposure to multiple heavy metals and glyphosate may contribute to Sri Lankan agricultural nephropathy. BMC Nephrol. 2015;16:103.

85. Orr SE, Bridges CC. Chronic Kidney Disease and Exposure to Nephrotoxic Metals. Int J Mol Sci. 2017 May 12;18(5). pii: E1039. doi: 10.3390/ijms18051039. Review.

86. Roncal Jimenez CA, Ishimoto T, Lanaspa MA, Rivard CJ, Nakagawa T, Ejaz AA, et al. Fructokinase activity mediates dehydrationinduced renal injury. Kidney Int. 2014;86(2):294-302.

87. Coca SG, Singanamala S, Parikh CR. Chronic kidney disease after acute kidney injury: a systematic review and meta-analysis. Kidney Int. 2012;81(5):442-8.

88. Sawhney S, Mitchell M, Marks A, Fluck N, Black C. Long-term prognosis after acute kidney injury (AKI): what is the role of baseline kidney function and recovery? A systematic review. BMJ Open. 2015;5(1):e006497.

89. Crowe J. Heat exposure and health outcomes in Costa Rican sugarcane harvesters. Umeå, Sweden: Umeå University; 2014. 
90. Crowe J, Nilsson M, Kjellstrom T, Wesseling C. Heat-related symptoms in sugarcane harvesters. Am J Ind Med. 2015;58(5):541-8.

91. Crowe J, Wesseling C, Solano BR, Umana MP, Ramirez AR, Kjellstrom T, et al. Heat exposure in sugarcane harvesters in Costa Rica. Am J Ind Med. 2013;56(10):1157-64.

92. Roncal-Jimenez C, Garcia-Trabanino R, Barregard L, Lanaspa MA, Wesseling C, Harra T, et al. Heat Stress Nephropathy From Exercise-Induced Uric Acid Crystalluria: A Perspective on Mesoamerican Nephropathy. Am J Kidney Dis. 2016;67(1):20-30.

93. Herath C, Jayasumana C, De Silva P, De Silva PHC, Siribaddana S, De Broe ME. Kidney Diseases in Agricultural Communities: A Case Against Heat-Stress Nephropathy. Kidney Int Rep. 2018;3(2):271-80.

94. Ramirez-Rubio O, Amador JJ, Kaufman JS, Weiner DE, Parikh CR, Khan U, et al. Urine biomarkers of kidney injury among adolescents in Nicaragua, a region affected by an epidemic of chronic kidney disease of unknown aetiology. Int J Occup Environ Health. 2016;31(3):424-32.
95. Gonzalez-Quiroz M, Pearce N, Caplin B, Nitsch D. What do epidemiological studies tell us about chronic kidney disease of undetermined cause in Meso-America? A systematic review and meta-analysis. Clin Kidney J. 2018;11(4):496-506.

96. Gonzalez-Quiroz M, Smpokou ET, Silverwood RJ, Camacho A, Faber D, Garcia BR, et al. Decline in Kidney Function among Apparently Healthy Young Adults at Risk of Mesoamerican Nephropathy. J Am Soc Nephrol. 2018;29(8):2200-12.

Manuscript received on 18 October 2018. Accepted for publication on 19 December 2018

\section{Factores de riesgo para la enfermedad renal crónica de causas no tradicionales: una revisión sistemática}

RESUMEN Objetivos. Evaluar las posibles asociaciones de la enfermedad renal crónica de etiología incierta o no tradicional (ERCnT) con los agroquímicos, el estrés por calor, los metales pesados y otros factores señalados en la bibliografía de cualquier región del mundo y en cualquier período.

Métodos. La presente es una revisión sistemática de las exposiciones más frecuentes que se sospecha podrían ser posibles causas de la ERCnT. Se realizó una búsqueda en las bases de datos electrónicas de PubMed, LILACS y World Wide Science, entre otras fuentes. Se incluyeron solamente estudios de calidad media y alta. La síntesis de la evidencias incluyó síntesis narrativa, metanálisis y metarregresión.

Resultados. Se incluyeron cuatro revisiones sistemáticas y 61 estudios primarios. Los resultados del metaanálisis sugieren que la exposición a agroquímicos y el trabajo agrícola aumentan el riesgo de ERCnT, pero esto solo alcanzó un nivel significativo con respecto al trabajo agrícola. Al excluir los estudios transversales, la exposición a agroquímicos se tornó significativa. Sin embargo, existe una heterogeneidad sustancial en las magnitudes del efecto.

Conclusiones. Con base en las pruebas científicas existentes y en el principio de precaución, es importante aplicar medidas preventivas para mitigar el daño ocasionado por la ERCnT tanto para los agricultores como para sus comunidades (es decir, mejoras en las condiciones de trabajo, uso prudente de agroquímicos, etc.). Es necesario aumentar la investigación de alta calidad para medir el impacto y ampliar la base de pruebas científicas.

Palabras clave Insuficiencia renal crónica; enfermedades de los trabajadores agrícolas; agroquímicos; agotamiento por calor; metaanálisis. 


\section{Fatores de risco para doença renal crônica associada a causas não tradicionais: revisão sistemática}

RESUMO Objetivos. Avaliar as associações em potencial entre doença renal crônica de etiologia incerta ou não tradicional e produtos agroquímicos, estresse térmico, metais pesados e outros fatores identificados na literatura em qualquer região do globo ou espaço de tempo.

Métodos. Trata-se de uma revisão sistemática dos tipos mais comuns de exposição suspeitas de serem possíveis causas de doença renal crônica de etiologia incerta ou não tradicional. Foram pesquisadas as bases de dados eletrônicas PubMed, LILACS, World Wide Science, entre outras fontes. Somente foram incluídos estudos de qualidade intermediária e alta. Síntese narrativa, meta-análise e metarregressão foram usadas para sumarizar as evidências.

Resultados. Este estudo compreendeu quatro estudos de revisão sistemática e 61 estudos primários. Os resultados da meta-análise indicaram que a exposição a produtos agroquímicos e o trabalho na agricultura aumentam o risco de doença renal crônica de etiologia incerta ou não tradicional, com risco significativo apenas para o trabalho na agricultura. Após a exclusão dos estudos transversais, a exposição a produtos agroquímicos também representou um risco significativo. Porém, observou-se considerável heterogeneidade nos tamanhos do efeito.

Conclusões. Diante das evidências existentes e com base no princípio da precaução, é importante implementar medidas preventivas para atenuar os danos causados pela doença renal crônica de etiologia incerta ou não tradicional aos trabalhadores e às comunidades agrícolas, como melhoria das condições de trabalho e manipulação cautelosa dos produtos agroquímicos, entre outros. Faz-se necessário realizar outras pesquisas de alta qualidade para avaliar o impacto e aumentar a base de evidências.

Palavras-chave Insuficiência renal crônica; doenças dos trabalhadores agrícolas; agroquímicos; exaustão por calor; metanálise. 